\title{
A Portfolio Selection Model Based on the Interval Number
}

\author{
Jiangshan Hu, ${ }^{1}$ Yunyun Sui $\mathbb{D}^{1},{ }^{1}$ and Fang $\mathrm{Ma}^{2}$ \\ ${ }^{1}$ School of Mathematics and Information Science, Weifang University, Weifang 261061, China \\ ${ }^{2}$ School of Science, Shenyang University of Technology, Shenyang 110023, China
}

Correspondence should be addressed to Yunyun Sui; suiyunyun1231@163.com

Received 25 April 2021; Accepted 25 May 2021; Published 2 June 2021

Academic Editor: Rongwei Guo

Copyright ( 92021 Jiangshan Hu et al. This is an open access article distributed under the Creative Commons Attribution License, which permits unrestricted use, distribution, and reproduction in any medium, provided the original work is properly cited.

Traditional portfolio theory uses probability theory to analyze the uncertainty of financial market. The assets' return in a portfolio is regarded as a random variable which follows a certain probability distribution. However, it is difficult to estimate the assets return in the real financial market, so the interval distribution of asset return can be estimated according to the relevant suggestions of experts and decision makers, that is, the interval number is used to describe the distribution of asset return. Therefore, this paper establishes a portfolio selection model based on the interval number. In this model, the semiabsolute deviation risk function is used to measure the portfolio's risk, and the solution of the model is obtained by using the order relation of the interval number. At the same time, a satisfactory solution of the model is obtained by using the concept of acceptability of the interval number. Finally, an example is given to illustrate the practicability of the model.

\section{Introduction}

Portfolio selection refers to the way in which investors allocate a certain proportion of their wealth to a number of different assets so as to spread risks among multiple assets and obtain some stable returns. Markowitz [1] created the classic portfolio theory in 1952, which laid the foundation of modern finance. In this theory, the covariance of all the securities in the portfolio was required, which was a considerable amount of calculation at that time, but difficult to achieve in practical application. Therefore, later, scholars constantly proposed improved optimization methods and thus put forward new portfolio models (e.g., [2-5]). In 1963, the capital asset pricing model (abbreviated as CAPM) proposed by Sharp [2] divided risks into systematic risks and nonsystematic risks on the basis of the model proposed by Markowitz. Markowitz [3] proposed a semivariance model. Mao [4] and Swalm [5] used the risk that the uncertain return is lower than the expected return to measure the investment risk and established the mean-semivariance portfolio selection model. In 1991, Konno and Yamazaki [6] proposed the absolute deviation risk function and constructed a mean-absolute deviation portfolio optimization model. Since then, scholars have also proposed many portfolio optimization models based on different risk measures, such as semiabsolute deviation model [7], valueat-risk (VaR) model [8-11], and conditional value-at-risk $(\mathrm{CVaR})$ model [12]. Since each measure of risk performs best in its own area and not necessarily in others, it is still up in the air whether there is a single measure of risk that is best for all portfolios $[13,14]$. In this paper, we will use the semiabsolute deviation absolute risk function to measure the risk of the portfolio.

Uncertainty exists everywhere, and scholars use various methods to study it [15-21]. Traditional portfolio theory uses probability theory to analyze the uncertainty in the financial market. However, due to the nonrandom factors such as social, economic, political, psychological, and other factors existing in the real financial market, other technologies are needed to deal with the uncertainty, such as possibility theory and fuzzy set theory. Possibility theory is an important theory of fuzzy sets that was first proposed by Zadeh [22] and developed by Dubois and Prade [23] (see [24-27], for more details). Portfolio models based on theory of possibility have been fruitful (see [28-35]). In these possibilistic portfolio selection models, it is assumed that the possibility distribution of asset return in the portfolio is known, but in reality, it is often not so. The interval number 
is a relatively simple fuzzy number, which is easy for experts and decision makers to estimate the interval number of fuzzy parameters in a certain precision range on the basis of comprehensive analysis of the influence of various factors. So far, there have been many reports using interval number theory to study portfolio selection, such as literature [36-42].

Lai et al. [37] gave the noninferior solutions of linear programming problems with interval coefficients. In [38], Ida regarded the portfolio problem with interval and fuzzy objective function coefficients as a kind of multiobjective problem containing uncertainty and gave its optimistic and pessimistic solutions. Giove et al. [39] established a portfolio model by taking securities' price as the interval variable and solved the model by using the minimax regret method. Bhattacharyya et al. [40] constructed a mean-varianceskewness portfolio model using interval numbers and used a hybrid intelligent algorithm (HIA) to solve the model. Liu [41] used an interval number to represent the expected return of an asset. According to the concept of mean-absolute deviation function, a pair of two-level portfolio model was constructed, and the upper and lower bounds of investment returns in the portfolio selection problem were calculated. Based on the semiabsolute deviation risk function proposed by Mansini and Speranza [43], a mean-semiabsolute deviation portfolio selection model with respect to the interval number will be established. The order relation of the interval number is very important for obtaining the solution of the model, so the order relation of the interval in [44] will be used to obtain the solution of the constructed model. At the same time, the satisfactory solution of the model is given according to the acceptability [45].

The rest of this paper is organized as follows. In Section 2, we will do some preliminary work and give the basic concepts and some notations that will be used later. In Section 3, the portfolio selection model construction and the solution of the model will be introduced in detail. To obtain the solution for the interval-valued programming model, the order relation and the acceptability of interval numbers are used to transform the model into a general programming model. Section 4 provides a numerical example to illustrate the proposed approach. Section 5 provides the conclusion.

\section{Preliminaries}

In this paper, concepts and operations related to interval numbers will be used. This section will briefly review the relevant concepts.

Definition 1 (see [46]). Given two interval numbers $a=$ $\left[a_{-}, a_{+}\right]$and $b=\left[b_{-}, b_{+}\right]$and a real number $\lambda$, then

(i) $a \pm b=\left[a_{-} \pm b_{-}, a_{+} \pm b_{+}\right]$.

(ii) $\lambda a= \begin{cases}{\left[\lambda a_{-}, \lambda a_{+}\right],} & \text {for } \lambda \geq 0, \\ {\left[\lambda a_{+}, \lambda a_{-}\right],} & \text {for } \lambda<0 .\end{cases}$

The interval number is a special fuzzy number whose membership function takes value 1 over the interval and 0 anywhere else, as discussed in detail by Hansen [47] and Alefeld and Herzberger [46]. The operations related to interval numbers are as follows.
Definition 2 (see [48-50]). Let $a=\left[a_{-}, a_{+}\right]$and $b=\left[b_{-}, b_{+}\right]$ be two interval numbers. We define the order relation $\leq$ between $a$ and $b$ as

$$
\begin{aligned}
& \text { (1) } a \leq b \text { if and only if } m(a) \leq m(b), \\
& \text { (2) } a<b \text { if and only if } a \leq b \text { and } a \neq b,
\end{aligned}
$$

where $m(a)=(1 / 2)\left(a_{-}+a_{+}\right)$is the midpoints of the interval numbera.

Specifically, if $a_{+} \leq b_{-}$, then the inequality relationship $a \leq b$ is optimistic and satisfactory. On the contrary, if $a_{+}>b_{-}$, the inequality relationship $a \leq b$ is pessimistic and satisfactory.

Definition 3 (see [51]). Given $a=\left[a_{-}, a_{+}\right]$and $b=\left[b_{-}, b_{+}\right]$, then $\lambda(a \leq b)=(m(b)-m(a)) /(\omega(b)+\omega(a))$ is the acceptability of $a \leq b$, where $m(a)$ and $\omega(a)$ are the midpoints and radius of the interval number $a$, respectively.

The notations used in this article are given below:

$p_{k t 0}$ : the opening price of the $k$ thsecurity at period $t$

$p_{k t c}$ : the closing price of the $k$ th security at period $t$

$r_{k t}:\left(p_{k t c}-p_{k t 0}\right) / p_{k t 0}=$ the return of asset $k$ at period $t$

$T$ : the total periods

$r_{k}:(1 / T) \sum_{t=1}^{T} r_{k t}=$ the return of asset $k$

$r_{f}$ : the return of the risk-free asset

$x_{k}$ : the percentage of assets that are invested in $k$

$w_{t}(x)$ : the portfolio's risk at period $t$

$W(x)$ : the portfolio's risk

$R$ : the portfolio's return

\section{Model Foundation}

Let us consider a market consisting of a riskless assets and $n$ stocks. As usual, we assume that there are no costs or taxes on trading, all assets are infinitely divisible, and short sales is not allowed.

Thus, the portfolio's return $R$ can be written as

$$
R=\sum_{k=1}^{n} x_{k} r_{k}+r_{f}\left(1-\sum_{k=1}^{n} x_{k}\right) .
$$

To set up a portfolio selection model, the following values need to be given.

First is the expected return of the portfolio's return $\widetilde{R}$.

The expected return on security $k$ is $\widetilde{r}_{k}=\left[r_{k}, \overline{r_{k}}\right]$. Thus, $\widetilde{R}$ is given by

$$
\widetilde{R}=\sum_{k=1}^{n}\left[\underline{r_{k}}, \overline{r_{k}}\right] x_{k}+r_{f}\left(1-\sum_{k=1}^{n} x_{k}\right) .
$$

Secondly, the risk of the portfolio is as follows.

As mentioned in Section 1, there is no single risk measure that is best for all portfolios, so the risk in this paper will be measured by the semiabsolute deviation function. The semiabsolute deviation of the portfolio in period $t$ can be calculated as follows: 


$$
w_{t}(x)=\left|\min \left\{0, \sum_{k=1}^{n}\left(r_{k t}-r_{k}\right) x_{k}\right\}\right|=\max \left\{0, \sum_{k=1}^{n}\left(r_{k}-r_{k t}\right) x_{k}\right\}, \quad t=1,2, \ldots, T .
$$

The risk of the portfolio is given by $(1 / T) \sum_{t=1}^{T} w_{t}(x)$.

So,

$$
\begin{aligned}
W(x) & =\frac{1}{T} \sum_{t=1}^{T}\left|\min \left\{0, \sum_{k=1}^{n}\left(r_{k t}-r_{k}\right) x_{k}\right\}\right| \\
& =\frac{1}{T} \sum_{t=1}^{T}\left[\max \left\{0, \sum_{k=1}^{n}\left(\underline{r_{k}}-r_{k t}\right) x_{k}\right\}, \max \left\{0, \sum_{k=1}^{n}\left(\overline{r_{k}}-r_{k t}\right) x_{k}\right\}\right] \\
& =\frac{1}{T} \sum_{t=1}^{T}\left[\frac{\sum_{k=1}^{n}\left(\underline{r_{k}}-r_{k t}\right) x_{k}+\left|\sum_{k=1}^{n}\left(\underline{r_{k}}-r_{k t}\right) x_{k}\right|}{2}, \frac{\sum_{k=1}^{n}\left(\overline{r_{k}}-r_{k t}\right) x_{k}+\left|\sum_{k=1}^{n}\left(\overline{r_{k}}-r_{k t}\right) x_{k}\right|}{2}\right] \\
& =\frac{1}{T} \sum_{t=1}^{T}\left[\underline{w}_{t}(x), \bar{w}_{t}(x)\right],
\end{aligned}
$$

where

$$
\begin{aligned}
& \underline{w}_{t}(x)=\frac{\left(\sum_{k=1}^{n}\left(\underline{r_{k}}-r_{k t}\right) x_{k}+\left|\sum_{k=1}^{n}\left(\underline{r_{k}}-r_{k t}\right) x_{k}\right|\right)}{2}, \\
& \bar{w}_{t}(x)=\frac{\left(\sum_{k=1}^{n}\left(\overline{r_{k}}-r_{k t}\right) x_{k}+\left|\sum_{k=1}^{n}\left(\overline{r_{k}}-r_{k t}\right) x_{k}\right|\right)}{2} .
\end{aligned}
$$

Therefore, a portfolio selection model based on riskreturn trade-off can be established:

$$
\left\{\begin{array}{l}
\min W(x), \\
\text { s.t. } \widetilde{R} \geq \mu, \sum_{k=1}^{n} x_{k} \leq 1,0 \leq l_{k} \leq x_{k} \leq h_{k}, \quad k=1,2, \ldots, n,
\end{array}\right.
$$

where $\mu$ is a minimum threshold at which investors can tolerate the expected rate of return on their portfolio and set $\mu=\left[\mu^{-}, \mu^{+}\right]$and $l_{k}$ and $h_{k}$ represent, respectively, the lower and the upper bounds on investment in asset $k$, $k=1,2, \ldots, n$.

As can be seen from equations (3) and (5), equation (7) can be transformed into

$$
\left\{\begin{array}{l}
\min W(x)=\frac{1}{T} \sum_{t=1}^{T}\left[\underline{w}_{t}(x), \bar{w}_{t}(x)\right], \\
\text { s.t. } \sum_{k=1}^{n}\left[\underline{r_{k}}, \overline{r_{k}}\right] x_{k}+r_{f}\left(1-\sum_{k=1}^{n} x_{k}\right) \geq\left[\mu^{-}, \mu^{+}\right], \\
\sum_{k=1}^{n} x_{k} \leq 1, \\
0 \leq l_{k} \leq x_{k} \leq h_{k}, \quad k=1,2, \ldots, n .
\end{array}\right.
$$

$$
0 \leq l_{k} \leq x_{k} \leq h_{k}, \quad k=1,2, \ldots, n .
$$

This is an interval-valued linear programming problem. For the solution method of interval-valued linear programming, scholars have carried out a lot of research and put forward some solutions. For example, Yoon [52] proposed 
the error analysis method. Bryson and Mobolurin [53] proposed the linear programming method. Romelfangerf et al. [54] studied the solution method of linear programming with the interval number as the coefficient of objective function. Liu and Iwamura [55] transformed interval number linear programming into a two-objective programming problem:

$$
\left\{\begin{array}{l}
\max \bar{W}(x)=-\frac{1}{T} \sum_{t=1}^{T} \bar{w}_{t}(x), \\
\max \bar{W}(x)=-\frac{1}{T} \sum_{t=1}^{T} \underline{w}_{t}(x), \\
\text { s.t. } \sum_{k=1}^{n}\left[\underline{r_{k}}, \overline{r_{k}}\right] x_{k}+r_{f}\left(1-\sum_{k=1}^{n} x_{k}\right) \geq\left[\mu^{-}, \mu^{+}\right], \\
\sum_{k=1}^{n} x_{k} \leq 1, \\
0 \leq l_{k} \leq x_{k} \leq h_{k}, \quad k=1,2, \ldots, n .
\end{array}\right.
$$

$$
\begin{aligned}
H(x) & =\frac{1}{T} \sum_{t=1}^{T}\left[(1-b) \bar{w}_{t}(x)+b \underline{w}_{t}(x)\right] \\
& =\frac{1}{T} \sum_{t=1}^{T}\left[(1-b) \frac{\left(\sum_{k=1}^{n}\left(\overline{r_{k}}-r_{k t}\right) x_{k}+\left|\sum_{k=1}^{n}\left(\overline{r_{k}}-r_{k t}\right) x_{k}\right|\right)}{2}+b \frac{\left.\left(\sum_{k=1}^{n}\left(\underline{r_{k}}-r_{k t}\right) x_{k}+\left|\sum_{k=1}^{n}\left(\underline{r}_{k}-r_{k t}\right) x_{k}\right|\right)\right]}{2}\right] \\
& =\sum_{k=1}^{n} \frac{(1-b) \xi_{k}+b \eta_{k}}{2 T} x_{k}+\frac{1}{2} \sum_{t=1}^{T}\left[(1-b) \frac{\left|\sum_{k=1}^{n}\left(\overline{r_{k}}-r_{k t}\right) x_{k}\right|}{T}+b \frac{\mid \sum_{k=1}^{n}\left(\frac{\left.r_{k}-r_{k t}\right)}{T}\left|x_{k}\right|\right]}{T}\right] \\
& =\sum_{k=1}^{n} \frac{(1-b) \xi_{k}+b \eta_{k}}{2 T} x_{k}+\frac{1}{2} \sum_{t=1}^{T}\left[(1-b) \frac{u_{t}}{T}+b \frac{v_{t}}{T}\right]
\end{aligned}
$$

where

$$
\begin{aligned}
\xi_{k} & =\sum_{t=1}^{T}\left(\overline{r_{k}}-r_{k t}\right), \\
\eta_{k} & =\sum_{t=1}^{T}\left(\underline{r_{k}}-r_{k t}\right), \\
u_{t} & =\left|\sum_{k=1}^{n}\left(\overline{r_{k}}-r_{k t}\right) x_{k}\right|, \\
v_{t} & =\left|\sum_{k=1}^{n}\left(\underline{r_{k}}-r_{k t}\right) x_{k}\right|,
\end{aligned}
$$

Chankong and Haimes [56] transformed the abovementioned two-objective programming problem (13) into the following parameter programming problem:

$$
\left\{\begin{array}{l}
\max \bar{W}(x)=\frac{1}{T} \sum_{t=1}^{T}\left[-(1-b) \bar{w}_{t}(x)-b \underline{w}_{t}(x)\right], \\
\text { s.t. } \widetilde{R} \geq\left[\mu^{-}, \mu^{+}\right], \sum_{k=1}^{n} x_{k} \leq 1,0 \leq l_{k} \leq x_{k} \leq h_{k}, \quad k=1,2, \ldots, n .
\end{array}\right.
$$

The solution of model (12) is also the solution of the following model:

$$
\left\{\begin{array}{l}
\min H(x)=\frac{1}{T} \sum_{t=1}^{T}\left[(1-b) \bar{w}_{t}(x)+b \underline{w}_{t}(x)\right], \\
\text { s.t. } \widetilde{R} \geq\left[\mu^{-}, \mu^{+}\right], \sum_{k=1}^{n} x_{k} \leq 1,0 \leq l_{k} \leq x_{k} \leq h_{k}, \quad k=1,2, \ldots, n .
\end{array}\right.
$$

Because 
According to Definition 1, (16) can be transformed into

$$
\left\{\begin{array}{l}
\min H(x)=\frac{1}{T} \sum_{t=1}^{T}\left[(1-b) \bar{w}_{t}(x)+b \underline{w}_{t}(x)\right] \\
\text { s.t. }\left[\sum_{k=1}^{n} \underline{r_{k}} x_{k}+r_{f}\left(1-\sum_{k=1}^{n} x_{k}\right), \sum_{k=1}^{n} \bar{r}_{k} x_{k}+r_{f}\left(1-\sum_{k=1}^{n} x_{k}\right)\right] \geq\left[\mu^{-}, \mu^{+}\right] \\
\sum_{k=1}^{n} x_{k} \leq 1, \\
0 \leq l_{k} \leq x_{k} \leq h_{k}, \quad k=1,2, \ldots, n .
\end{array}\right.
$$

In order to obtain the solution of (17), the order relation of the interval number in Definition 2 and (14) can be used to convert (17) into

$$
\left\{\begin{array}{l}
\min H(x)=\sum_{k=1}^{n} \frac{(1-b) \xi_{k}+b \eta_{k}}{2 T} x_{k}+\frac{1}{2} \sum_{t=1}^{T}\left[(1-b) \frac{u_{t}}{T}+b \frac{v_{t}}{T}\right] \\
\text { s.t. } \frac{1}{2}\left(\sum_{k=1}^{n} \underline{r}_{k} x_{k}+\sum_{k=1}^{n} \overline{r_{k}} x_{k}\right)+r_{f}\left(1-\sum_{k=1}^{n} x_{k}\right) \geq \frac{1}{2}\left(\mu^{-}+\mu^{+}\right), \\
u_{t}+\sum_{k=1}^{n}\left(\overline{r_{k}}-r_{k t}\right) x_{k} \geq 0, \quad t=1,2, \ldots, T, \\
u_{t}-\sum_{k=1}^{n}\left(\overline{r_{k}}-r_{k t}\right) x_{k} \geq 0, \quad t=1,2, \ldots, T, \\
\sum_{k=1}^{n} x_{k} \leq 1, \\
v_{t}+\sum_{k=1}^{n}\left(\underline{r_{k}}-r_{k t}\right) x_{k} \geq 0, \quad t=1,2, \ldots, T, \\
0 \leq l_{k} \leq x_{k} \leq h_{k}, \quad k=1,2, \ldots, n . \\
\left.r_{k}-r_{k t}\right) x_{k} \geq 0, \quad t=1,2, \ldots, T
\end{array}\right.
$$

Then, (18) is a parameter-planning problem, which can be solved by Matlab, Lingo, and other software.
Definition 4. The optimal solution to (18) is called an interval-valued efficient portfolio. 
The lower bounds of all the interval-valued efficient portfolios construct the interval-valued lower efficient frontier. The upper bounds of all the interval-valued efficient portfolios construct the interval-valued upper efficient frontier.

Meanwhile, based on the acceptability, (17) can also be transformed into
TABLE 1: The expected return of the five securities.

\begin{tabular}{lc}
\hline Code & $\widetilde{r}_{k}=\left[\underline{r_{k}}, \overline{r_{k}}\right]$ \\
\hline$S 1$ & {$[-0.557,0.341]$} \\
S2 & {$[-0.170,0.306]$} \\
S3 & {$[-0.381,0.953]$} \\
S4 & {$[-0.316,0.258]$} \\
S5 & {$[-0.503,0.156]$} \\
\hline
\end{tabular}

$$
\left\{\begin{array}{l}
\min H(x)=\frac{1}{T} \sum_{t=1}^{T}\left[(1-b) \bar{w}_{t}(x)+b \underline{w}_{t}(x)\right], \\
\text { s.t. } \lambda\left(\left[\sum_{k=1}^{n} \underline{r}_{k} x_{k}+r_{f}\left(1-\sum_{k=1}^{n} x_{k}\right), \sum_{k=1}^{n} \bar{r}_{k} x_{k}+r_{f}\left(1-\sum_{k=1}^{n} x_{k}\right)\right] \geq\left[\mu^{-}, \mu^{+}\right]\right) \geq \alpha, \\
\sum_{k=1}^{n} x_{k} \leq 1, \\
0 \leq l_{k} \leq x_{k} \leq h_{k}, \quad k=1,2, \ldots, n,
\end{array}\right.
$$

where $\alpha$ is the minimum value of acceptability.

According to Definition 3, we can obtain

$$
\left\{\begin{array}{l}
\min H(x)=\frac{1}{T} \sum_{t=1}^{T}\left[(1-b) \bar{w}_{t}(x)+b \underline{w}_{t}(x)\right], \\
\text { s.t. } \frac{\sum_{k=1}^{n} \underline{r_{k}} x_{k}+\sum_{k=1}^{n} \overline{r_{k}} x_{k}+2 r_{f}\left(1-\sum_{k=1}^{n} x_{k}\right)-\left(\mu^{-}+\mu^{+}\right)}{\left(\sum_{k=1}^{n} \overline{r_{k}} x_{k}-\sum_{k=1}^{n} \underline{r_{k}} x_{k}\right)-\left(\mu^{+}-\mu^{-}\right)} \geq \alpha, \\
\sum_{k=1}^{n} x_{k} \leq 1, \\
0 \leq l_{k} \leq x_{k} \leq h_{k}, \quad k=1,2, \ldots, n .
\end{array}\right.
$$

Thus, a satisfactory solution of the model is obtained, and an acceptable efficient portfolio is obtained.

\section{Numerical Example}

In order to illustrate the practicality of this model, we select five securities and one risk-free asset from the Chinese stock market for investment. Annual data from 2016 to 2020 were selected. Table 1 shows the expected return.

Let the risk-free asset be a treasury bond. We use the one-year treasury bond rate as the return rate of the riskless asset. So, we get the return on risk-free asset $r=2.8 \%$ if the lower bound of the investment ratio $x_{k}$ must be $l=\{0.01,0.03,0.01,0.01,0\}$ and the upper bound $h=$ $\{0.3,0.4,0.1,0.5,0.3\}$.
Table 2 shows the effective portfolios of model (18) with different $\mu$ s when $b=0.1$. Figure 1 gives some efficient portfolios for model (18).

As can be seen from Table 2,

(1) The lower limit of the minimum expected return rate remains unchanged. With the increase of the upper limit, the investment proportion of $S 5$ will increase first. When the investment proportion of $S 5$ reaches its upper limit, the investment proportion of $S 1$ will be increased again.

(2) As the minimum expected return rate increases, so does portfolio risk.

(3) When the minimum expected return rate increases to a certain value, the model will have no feasible solution.

Parameter $b$ is the risk preference coefficient. The larger $b$ is, the more investors are inclined to avoid risk; the smaller $b$ is, the more investors are inclined to risk. As can be seen from Table 3, $b$ reflects investors' risk preference. The bigger $b$ is, the less risk the portfolio is and the more cautious the investor is. Figure 2 also reflects the relationship between portfolio risk and the risk preference coefficient $b$.

Model (19) presents the acceptable solution of the portfolio model based on the acceptability. The upper and lower limits of the portfolio are given as $h=$ $\{0.3,0.4,0.2,0.5,0.3\}$ and $l=\{0.01,0,03,0.01,0.01,0\}$, respectively, and Tables 4 and 5, respectively, show the acceptable solution of model (20) and the risk of the portfolio for different $\mu$ swhen $\alpha=0.1$ and $\alpha=0.2$.

As can be seen from Table 4,

(1) With the increase of $\mu$, the investment proportion of S3 increases first. When $\mu$ increases to a certain 
TABLE 2: The investment proportion and risk for different $\mu$ s in (18) when $b=0.1$

\begin{tabular}{lccccccc}
\hline$\mu$ & $S 1$ & $S 2$ & $S 3$ & $S 4$ & $S 5$ & Risk & $\sum_{k=1}^{5} x_{k}$ \\
\hline$[0.04,0.04]$ & 0.010 & 0.030 & 0.010 & 0.010 & 0.118 & 0.036 & 0.178 \\
{$[0.04,0.05]$} & 0.010 & 0.030 & 0.010 & 0.010 & 0.153 & 0.042 & 0.213 \\
{$[0.04,0.06]$} & 0.010 & 0.030 & 0.010 & 0.010 & 0.187 & 0.048 & 0.247 \\
{$[0.04,0.07]$} & 0.010 & 0.030 & 0.010 & 0.010 & 0.221 & 0.054 & 0.281 \\
{$[0.04,0.08]$} & 0.010 & 0.030 & 0.010 & 0.010 & 0.256 & 0.060 & 0.316 \\
{$[0.04,0.09]$} & 0.010 & 0.030 & 0.010 & 0.010 & 0.290 & 0.066 & 0.350 \\
{$[0.04,0.10]$} & 0.054 & 0.030 & 0.010 & 0.010 & 0.300 & 0.080 & 0.404 \\
{$[0.04,0.11]$} & 0.116 & 0.030 & 0.010 & 0.010 & 0.300 & 0.097 & 0.466 \\
{$[0.04,0.12]$} & 0.178 & 0.030 & 0.010 & 0.010 & 0.300 & 0.114 & 0.528 \\
{$[0.04,0.14]$} & 0.300 & 0.030 & 0.010 & 0.220 & 0.300 & 0.182 & 0.860 \\
\hline
\end{tabular}

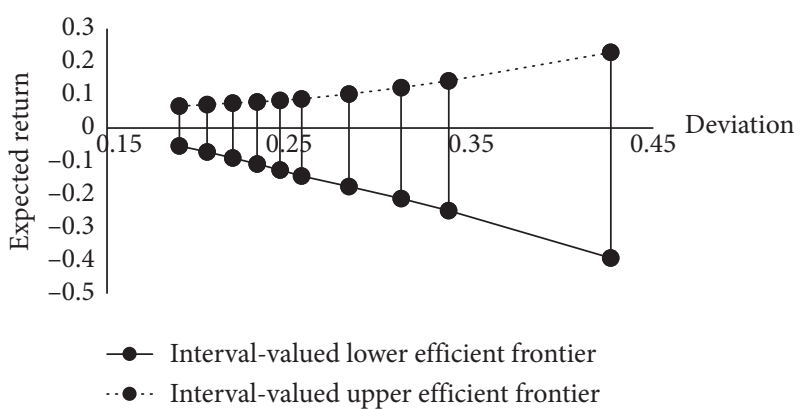

Figure 1: Some efficient portfolios for model (18).

TABLE 3: The investment risk for different $b s$ in (18).

\begin{tabular}{lccc}
\hline$b$ & Risk & $b$ & Risk \\
\hline 0 & 0.190 & 0.55 & 0.107 \\
0.1 & 0.182 & 0.6 & 0.097 \\
0.2 & 0.134 & 0.7 & 0.086 \\
0.3 & 0.128 & 0.8 & 0.078 \\
0.4 & 0.115 & 0.9 & 0.056 \\
0.5 & 0.109 & 1.0 & 0.045 \\
\hline
\end{tabular}

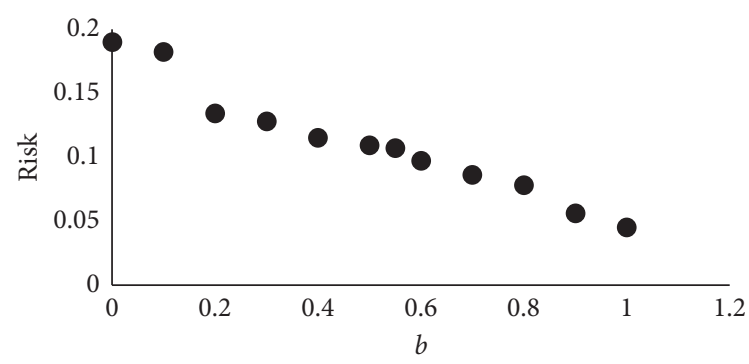

Figure 2: The scatter diagram of portfolio risk and the risk preference coefficient $b$.

extent, the investment proportion of $S 3$ reaches the upper limit of investment, and then, the investment proportion of $S 2$ increases.
TABLE 4: The investment proportion and risk for different $\mu$ s with $\alpha=0.1$ in (20).

\begin{tabular}{lccccccc}
\hline$\mu$ & $S 1$ & $S 2$ & $S 3$ & $S 4$ & $S 5$ & Risk & $\sum_{k=1}^{5} x_{k}$ \\
\hline$[0.03,0.03]$ & 0.010 & 0.030 & 0.034 & 0.010 & 0.010 & 0.028 & 0.094 \\
{$[0.03,0.04]$} & 0.010 & 0.030 & 0.058 & 0.010 & 0.010 & 0.040 & 0.118 \\
{$[0.03,0.05]$} & 0.010 & 0.030 & 0.081 & 0.010 & 0.010 & 0.052 & 0.141 \\
{$[0.03,0.06]$} & 0.010 & 0.030 & 0.105 & 0.010 & 0.010 & 0.063 & 0.165 \\
{$[0.03,0.07]$} & 0.010 & 0.030 & 0.128 & 0.010 & 0.010 & 0.075 & 0.188 \\
{$[0.03,0.08]$} & 0.010 & 0.030 & 0.152 & 0.010 & 0.010 & 0.087 & 0.212 \\
{$[0.03,0.09]$} & 0.010 & 0.030 & 0.175 & 0.010 & 0.010 & 0.098 & 0.235 \\
{$[0.03,0.10]$} & 0.010 & 0.030 & 0.199 & 0.010 & 0.010 & 0.110 & 0.259 \\
{$[0.03,0.11]$} & 0.010 & 0.293 & 0.200 & 0.010 & 0.010 & 0.157 & 0.523 \\
\hline
\end{tabular}

TABLE 5: The investment proportion and risk for different $\mu$ s with $\alpha=0.2$ in (20).

\begin{tabular}{lccccccc}
\hline$\mu$ & $S 1$ & $S 2$ & $S 3$ & $S 4$ & $S 5$ & Risk & $\sum_{k=1}^{5} x_{k}$ \\
\hline$[0.03,0.03]$ & 0.010 & 0.030 & 0.067 & 0.010 & 0.010 & 0.044 & 0.127 \\
{$[0.03,0.04]$} & 0.010 & 0.030 & 0.099 & 0.010 & 0.010 & 0.052 & 0.159 \\
{$[0.03,0.05]$} & 0.010 & 0.030 & 0.131 & 0.010 & 0.010 & 0.076 & 0.191 \\
{$[0.03,0.06]$} & 0.010 & 0.030 & 0.163 & 0.010 & 0.010 & 0.092 & 0.223 \\
{$[0.03,0.07]$} & 0.010 & 0.030 & 0.195 & 0.010 & 0.010 & 0.108 & 0.255 \\
\hline
\end{tabular}

(2) When $\mu$ increases to a certain extent, the model will have no feasible solution. When the acceptability of the expected return rate of the portfolio is not less than $\mu$ is 0.1 , the proportion of risky assets invested will continue to increase as $\mu$ increases, and so will the risk of the portfolio. Since $\alpha=0.1$, when $\mu$ reaches a certain level, the risk of the portfolio will no longer increase, and the investment proportion of risky assets will not change, that is, a part of the capital must be invested in the risk-free assets.

It can be seen from Table 5 that the law is similar to that in Table 4.

By comparing Tables 4 and 5 , it can be found that when $\mu$ is set to the same value, $\alpha$ is larger, the objective function value is larger, and the investment proportion of risky assets is also higher. That is to say, the greater the acceptability of the expected return rate of the portfolio is less than $\mu$, the greater the risk of the portfolio and the higher the proportion of risky assets' investment.

\section{Conclusions}

This paper takes the assets return as the interval number and uses the semiabsolute deviation function of the interval number to measure the portfolio's risk. Therefore, a portfolio selection model with mean-semiabsolute deviation based on the interval number is constructed. In this model, firstly, the lower bound of the investors' expected rate of return is also regarded as an interval number, which can better grasp investors' psychology and measure investors' expected return rate. Secondly, when solving the semiabsolute deviation portfolio selection model, a parameter which can reflect investors' risk preference is introduced, and this 
parameter can reflect investors' risk preference more intuitively. Finally, an application of the portfolio diversification problem is given by using a portfolio consisting of 5 risky assets and 1 risk-free asset. The results show that the introduced risk preference parameter can well reflect the investors' attitude to risk, and the lower bound of the expected return rate of this method is more elastic. The model can be used more widely and can describe the expected return rate of investment portfolio and the investors' attitude to risk more flexibly [56].

\section{Data Availability}

The data used to support the findings of this study are available from the corresponding author upon request.

\section{Conflicts of Interest}

The authors declare that there are no conflicts of interest regarding the publication of this paper.

\section{Acknowledgments}

This research was funded by the National Natural Science Foundation of China (11401438), the National Social Science Foundation Project of China (13CRK027), and the social science planning project of Shandong Province (21CTJJ04).

\section{References}

[1] H. Markowitz, "Portfolio selection," The Journal of Finance, vol. 7, no. 1, pp. 77-91, 1952.

[2] W. F. Sharpe, Portfolio Theory and Capital Markets, McGrawHill, New York, NY, USA, 1970.

[3] H. Markowitz, Portfolio Selection: Efficient Diversification of Investments, Yale University Press, New York, NY, USA, 1959.

[4] J. C. T. Mao, "Models of capital budgeting, E-V vs E-S," The Journal of Financial and Quantitative Analysis, vol. 4, no. 5, pp. 657-675, 1970.

[5] R. O. Swalm, "Utility theory--insights into risk taking," Harvard Business Review, vol. 44, pp. 123-136, 1966.

[6] H. Konno and H. Yamazaki, "Mean-absolute deviation portfolio optimization model and its applications to tokyo stock market," Management Science, vol. 37, no. 5, pp. 519-531, 1991.

[7] M. G. Speranza, "Linear programming model for portfolio optimization,” Finance, vol. 14, pp. 107-123, 1993.

[8] P. Jorion, "Risk2: measuring the risk in value at risk," $F i$ nancial Analysts Journal, vol. 52, no. 6, pp. 47-56, 1996.

[9] S. Basak and A. Shapiro, "Value-at-Risk-Based risk management: optimal policies and asset prices," Review of Financial Studies, vol. 14, no. 2, pp. 371-405, 2001.

[10] S. X. Chen and C. Y. Tang, "Nonparametric inference of valueat-risk for dependent financial returns," Journal of Financial Econometrics, vol. 3, no. 2, pp. 227-255, 2005.

[11] F.-Y. Chen, "Analytical VaR for international portfolios with common jumps," Computers \& Mathematics with Applications, vol. 62, no. 8, pp. 3066-3076, 2011.

[12] R. Mansini, W. Ogryczak, and M. G. Speranza, "Conditional value at risk and related linear programming models for portfolio optimization," Annals of Operations Research, vol. 152, no. 1, pp. 227-256, 2007.
[13] P. Byrne and S. Lee, "Different risk measures: different portfolio compositions?" Journal of Property Investment \& Finance, vol. 22, no. 6, pp. 501-511, 2004.

[14] H. Kandasamy, Portfolio Selection under Various Risk Measures, Clemson University, Clemson, South Carolina, 2008.

[15] X. Yi, R. Guo, and Y. Qi, "Stabilization of chaotic systems with both uncertainty and disturbance by the UDE-based control method," IEEE Access, vol. 8, pp. 62471-62477, 2020.

[16] D. Zhao, Y. Liu, Y. Liu, and X. Li, "Controllability for a class of semilinear fractional evolution systems via resolvent operators," Communications on Pure \& Applied Analysis, vol. 18, no. 1, pp. 455-478, 2019.

[17] C. Jiang, Akbar Zada, M. Tamer Senel, and T. Li, "Synchronization of bidirectional N-coupled fractional-order chaotic systems with ring connection based on antisymmetric structure," Advances in Difference Equations, vol. 16, Article ID 456, 2019.

[18] L. Liu, B. Li, and R. Guo, "Consensus control for networked manipulators with switched parameters and topologies," IEEE Access, vol. 9, pp. 9209-9217, 2021.

[19] C. Jiang, F. Zhang, and T. Li, "Synchronization and antisynchronization ofN-coupled fractional-order complex chaotic systems with ring connection," Mathematical Methods in the Applied Sciences, vol. 41, no. 7, pp. 2625-2638, 2018.

[20] D. Zhao and J. Mao, "New controllability results of fractional nonlocal semilinear evolution systems with finite delay," Complexity, vol. 2020, Article ID 7652648, 13 pages, 2020.

[21] T. Hou, Y. Liu, and F. Deng, "Stability for discrete-time uncertain systems with infinite Markov jump and time-delay," Science China Information Sciences, vol. 64, no. 5, pp. 1-11, 2021.

[22] L. A. Zadeh, "Fuzzy sets as a basis for a theory of possibility," Fuzzy Sets and Systems, vol. 1, no. 1, pp. 3-28, 1978.

[23] D. Dubois and H. Prade, "The mean value of a fuzzy number," Fuzzy Sets and Systems, vol. 24, pp. 279-300, 1978.

[24] C. Carlsson and R. Fullér, "On possibilistic mean value and variance of fuzzy numbers," Fuzzy Sets and Systems, vol. 122, no. 2, pp. 315-326, 2001.

[25] W. G. Zhang and Z. K. Nie, "On possibilistic variance of fuzzy numbers," Rough Sets, Fuzzy Sets, Data Mining, and Granular Computing, vol. 2639, pp. 398-402, 2003.

[26] C. Carlsson and R. Fullér, Possibility for Decision: A Possibilistic Approach to Real Life Decisions, Springer, Berlin, Germany, 2011.

[27] I. Georgescu, Possibility Theory and the Risk, Springer, Berlin, Germany, 2012.

[28] H. Tanaka, H. Nakayama, and A. Yanagimoto, "Possibility portfolio selection," in Proceedings of the 1995 IEEE International Conference on Fuzzy Systems, pp. 77-91, Yokohama, Japan, 1995.

[29] C. Carlsson, R. Fullér, and P. Majlender, "A possibilistic approach to selecting portfolios with highest utility score," Fuzzy Sets and Systems, vol. 131, no. 1, pp. 13-21, 2002.

[30] R. Fullér and P. Majlender, "On weighted possibilistic mean and variance of fuzzy numbers," Fuzzy Sets and Systems, vol. 136, no. 3, pp. 363-374, 2003.

[31] W.-G. Zhang, Y.-L. Wang, Z.-P. Chen, and Z.-K. Nie, "Possibilistic mean-variance models and efficient frontiers for portfolio selection problem," Information Sciences, vol. 177, no. 13, pp. 2787-2801, 2007.

[32] W. G. Zhang and Y. L. Wang, "Using fuzzy possibilistic mean and variance in portfolio selection model," Computational Intelligence and Security, vol. 3801, pp. 291-296, 2003. 
[33] W.-G. Zhang, "Possibilistic mean-standard deviation models to portfolio selection for bounded assets," Applied Mathematics and Computation, vol. 189, no. 2, pp. 1614-1623, 2007.

[34] W.-G. Zhang, W.-L. Xiao, and Y.-L. Wang, "A fuzzy portfolio selection method based on possibilistic mean and variance," Soft Computing, vol. 13, no. 6, pp. 627-633, 2009.

[35] Y. Sui, J. Hu, and F. Ma, "A possibilistic portfolio model with fuzzy liquidity constraint," Complexity, vol. 2020, Article ID 3703017, 10 pages, 2020.

[36] M. A. Parra, A. B. Terol, and M. V. R. Uria, "A fuzzy goal programming approach to portfolio selection," European Journal of Operational Research, vol. 133, pp. 287-297, 2001.

[37] K. K. Lai, S. Y. Wang, J. P. Xu, S. S. Zhu, and Y. Fang, "A class of linear interval programming problems and its application to portfolio selection," IEEE Transactions on Fuzzy Systems, vol. 10, no. 6, pp. 698-704, 2002.

[38] M. Ida, "Solutions for the portfolio selection problem with interval and fuzzy coefficients," Reliable Computing, vol. 10, no. 5, pp. 389-400, 2004.

[39] S. Giove, S. Funari, and C. Nardelli, "An interval portfolio selection problem based on regret function," European Journal of Operational Research, vol. 170, pp. 253-264, 2005.

[40] R. Bhattacharyya, S. Kar, S. Kar, and D. D. Majumder, "Fuzzy mean-variance-skewness portfolio selection models by interval analysis," Computers \& Mathematics with Applications, vol. 61, no. 1, pp. 126-137, 2011.

[41] S.-T. Liu, "The mean-absolute deviation portfolio selection problem with interval-valued returns," Journal of Computational and Applied Mathematics, vol. 235, no. 14, pp. 41494157, 2011.

[42] Y. Sui, J. Hu, and F. Ma, "A mean-variance portfolio selection model with interval-valued possibility measures," Mathematical Problems in Engineering, vol. 2020, pp. 1-12, 2020.

[43] R. Mansini and M. G. Speranza, "Heuristic algorithms for the portfolio selection problem with minimum transaction lots," European Journal of Operational Research, vol. 114, no. 2, pp. 219-233, 1999.

[44] H. Ishibuchi and H. Tanaka, "Multiobjective programming in optimization of the interval objective function," European Journal of Operational Research, vol. 48, no. 2, pp. 219-225, 1990.

[45] A. Sengupta, T. K. Pal, and D. Chakraborty, "Interpretation of inequality constraints involving interval coefficients and a solution to interval linear programming," Fuzzy Sets and Systems, vol. 119, no. 1, pp. 129-138, 2001.

[46] G. Alefeld and J. Herzberger, Introduction to Interval Computations, Academic Press, New York, NY, USA, 1983.

[47] E. Hansen, Global Optimization Using Interval Analysis, Marcel Dekker, New York, NY, USA, 1992.

[48] R. C. Young, "The algebra of many-valued quantities," Mathematische Annalen, vol. 104, no. 1, pp. 260-290, 1931.

[49] E. R. Moore, Methods and Applications of Interval Analysis, Prentice-Hall, London, UK, 1979.

[50] R. Moore and W. Lodwick, "Interval analysis and fuzzy set theory," Fuzzy Sets and Systems, vol. 135, no. 1, pp. 5-9, 2003.

[51] A. Sengupta and T. K. Pal, "On comparing interval numbers," European Journal of Operational Research, vol. 127, no. 1, pp. 28-43, 2000.

[52] K. Yoon, "The propagation of errors in multiple-attribute decision analysis: a practical approach," Journal of the Operational Research Society, vol. 40, no. 7, pp. 681-686, 1989.

[53] N. Bryson and A. Mobolurin, "An action learning evaluation procedure for multiple criteria decision making problems,"
European Journal of Operational Research, vol. 96, no. 2, pp. 379-386, 1997.

[54] H. Rommelfanger, R. Hanuscheck, and J. Wolf, "Linear programming with fuzzy objectives," Fuzzy Sets and Systems, vol. 29, no. 1, pp. 31-48, 1989.

[55] B. Baoding Liu and K. Kakuzo Iwamura, "A note on chance constrained programming with fuzzy coefficients," Fuzzy Sets and Systems, vol. 100, no. 1-3, pp. 229-233, 1998.

[56] V. Chankong and Y. Y. Haimes, Multiobjective Decision Making: Theory and Methodology, North Holland: Amsterdam, Netherlands, 1983. 